\section{HIF1 $\alpha$ delays premature senescence through the activation of MIF}

\author{
Scott M. Welford, ${ }^{1}$ Barbara Bedogni, ${ }^{1}$ \\ Katarina Gradin, ${ }^{2}$ Lorenz Poellinger, ${ }^{2}$ \\ Marianne Broome Powell, ${ }^{1}$ and \\ Amato J. Giaccia ${ }^{1,3}$
}

${ }^{1}$ Division of Radiation and Cancer Biology, Stanford

University, Stanford, California 94305, USA; ${ }^{2}$ Department of

Cell and Molecular Biology, Karolinska Institute, SE-171 77

Stockholm, Sweden

\begin{abstract}
Premature senescence in vitro has been attributed to oxidative stress leading to a DNA damage response. In the absence of oxidative damage that occurs at atmospheric oxygen levels, proliferation of untransformed cells continues for extended periods of time. We have investigated the role of the hypoxia-inducible factor $1 \alpha$ (HIF1 $\alpha)$ transcription factor in preventing senescence in aerobic and hypoxic conditions. Using embryonic fibroblasts from a conditional HIF1 $\alpha$ knockout mouse, we found that loss of HIF1 $\alpha$ under aerobic conditions significantly accelerated the onset of cellular senescence, and decreased proliferation under hypoxia. Furthermore, we identify the macrophage migration inhibitory factor (MIF) as a crucial effector of HIF1 $\alpha$ that delays senescence. Inhibition of MIF phenocopies loss of HIF1 $\alpha$. Our findings highlight a novel role for HIF1 $\alpha$ under aerobic conditions, and identify MIF as a target responsible for this function.
\end{abstract}

Supplemental material is available at http://www.genesdev.org.

Received July 19, 2006; revised version accepted October 24, 2006.

Cellular senescence has emerged as a programmed cellular stress response that is induced due to the accumulation of damage to a cell. Whether through the shortening of telomeres associated with a high number of cell divisions, activation of oncogenes, or DNA damage due to oxidative stress, induction of senescence in primary cells leads to an irreversible arrest phenotype that is characterized by the activation of the p53 and $\mathrm{Rb}$ proteins, as well as extensive chromatin modifications associated with the silencing of S-phase-promoting genes (Narita et al. 2003). In this way, senescence can be seen as a tumor suppressor mechanism that prevents excessive cellular divisions, or division of damaged cells (BenPorath and Weinberg 2005).

There is increasing evidence that senescence plays a critical role as a tumor suppressor in vivo. Senescent cells have been found recently in early-stage human

[Keywords: HIF1 $\alpha$; MIF; senescence; hypoxia; oxidative stress] ${ }^{3}$ Corresponding author.

E-MAIL giaccia@stanford.edu; FAX (650) 723-7382.

Article published online ahead of print. Article and publication date are online at http://www.genesdev.org/cgi/doi/10.1101/gad.1471106. prostate cancer specimens and premalignant melanocytic nevi, as well as in experimental models of lung adenocarcinoma and Ras-driven lymphoma (Braig et al. 2005; Chen et al. 2005; Collado et al. 2005; Michaloglou et al. 2005). These findings not only substantiate the significance of in vitro models of senescence, but also suggest novel therapeutic avenues aimed at reinitiating senescent programs in malignant cells (Lowe et al. 2004; Sharpless and DePinho 2005).

In normal tissue culture conditions, murine embryonic fibroblasts (MEFs) survive eight to 10 population doublings before they undergo premature cellular senescence. This senescence has been attributed to "culture shock" due to the nonphysiological conditions in which cells are grown (Sherr and DePinho 2000). Accordingly, it has been recently observed that senescence of MEFs in vitro can be abrogated by maintaining cells in a more physiological oxygen environment $\left(3 \% \mathrm{O}_{2}\right)$ (Parrinello et al. 2003). The mechanism leading to this reduction in senescence appears to be tied to the decrease in DNA damage that the cells endure in hyperoxic tissue culture conditions that are termed "normoxia" (i.e., atmospheric $\mathrm{O}_{2}$ levels, $21 \%$ ). A similar result has also been observed for oncogene-induced senescence, in which oncogenes such as Ras can induce premature senescence of MEFs (Serrano et al. 1997; Lee et al. 1999). When grown in the presence of antioxidants or in lower oxygen tensions, however, Ras-expressing MEFs continue to proliferate (Lee et al. 1999). These data suggest that reduction in oxidative damage due to reactive oxygen species (ROS) is sufficient to inhibit premature senescence.

Normal tissues are not typically exposed to the high levels of oxygen found in the environment. In vivo oxygen levels range from roughly $2 \%-3 \%$ in the brain, liver, and myocardium; $9 \%-10 \%$ in the spleen; and up to $13 \%-14 \%$ in the alveoli of the lung (Vaupel et al. 1989). Lower oxygen levels characterize normal and pathologic states including wound healing, ischemic disease, and cancer. The hypoxia-inducible factors (HIFs) are a family of transcriptional regulators that are important in the cellular response to hypoxia. They transcriptionally control a diverse number of genes including those involved in glycolytic metabolism, vascular remodeling, and erythropoeisis. HIFs are regulated primarily at the level of protein stability by the von Hippel Lindau protein (VHL), which directs the HIF $\alpha$ subunits to the proteosome for rapid degradation in oxic conditions (Kim and Kaelin 2004; Schofield and Ratcliffe 2004). In the mildly hypoxic conditions common to many tissues, HIF $\alpha$ subunits are stabilized and active (Stewart et al. 1982; Bedogni et al. 2005). Active HIF therefore correlates with resistance to premature senescence, both of which occur in physiological oxygen levels.

Whether HIFs play a direct role in preventing senescence under hypoxic conditions has not been determined. Recently, it has been observed in some endometrial cancer cell lines that modulation of the HIF pathway can affect senescence. Overexpression of a key negative regulator of HIFs (EGLN1), or use of a HIF inhibitor (YC-1), brought about proliferative arrest and the onset of a senescence-like phenotype (Kato et al. 2006). Collectively, these observations prompted us to ask whether HIFs were able to prevent senescence in a ge- 
netically defined system. In MEFs, the HIF1 complex is the primary functional member of the HIF family, as HIF $2 \alpha$ is sequestered in the cytoplasm and held transcriptionally inactive (Park et al. 2003). Therefore, we used conditional loxP HIF1 $\alpha$ MEFs to test the hypothesis that HIF1 may act to delay premature senescence. We found that HIF $1 \alpha$ does play a role in the enhanced proliferation of cells under low oxygen conditions, and modulates senescence in response to hyperoxic conditions $\left(21 \% \mathrm{O}_{2}\right)$. This effect was also seen when oxidative stress was induced by $\gamma$-irradiation to MEFs maintained in physiological oxygen tensions. We further found that the anti-senescent effect of HIF $1 \alpha$ is mediated in part by the transcriptional regulation of the macrophage migration inhibitory factor (MIF). Together, these findings offer new insights into the modulation of the tumor suppressor mechanism of senescence and its regulation under physiological conditions.

\section{Results and Discussion}

Loss of HIF1 $\alpha$ causes premature senescence in MEFs in aerobic conditions

In order to determine if HIFl $\alpha$ contributes to the prolonged life span of MEFs grown under low oxygen conditions (Parrinello et al. 2003), we derived MEFs from a conditional LoxP HIF $1 \alpha$ mouse (HIF $1 \alpha^{\mathrm{fl} / \mathrm{fl}} \mathrm{MEFs}$ ) (Ryan et al. 2000), and then infected them with Cre-expressing or empty adenoviruses (Ad-Cre or Ad-empty, respectively). Induction of HIFl $\alpha$ protein by hypoxia was significantly reduced in the Cre-infected cells $(-90 \%)$, demonstrating efficient excision of the HIF1 $\alpha$ gene (Fig. 1A). Hypoxic activation of a HIF1 target gene, GLUT1, was also ablated following Cre infection. These cells were cultured in either normoxic $\left(21 \% \mathrm{O}_{2}\right)$ or hypoxic $\left(2 \% \mathrm{O}_{2}\right)$ environments to determine how changes in HIF1 affect cell growth. As has been previously observed (Parrinello et al. 2003), wild-type MEFs grow significantly better in hypoxic conditions than in normoxia, such that after five passages there was a two log difference in the number of hypoxic cells compared with normoxic cells (Fig. 1B). At this point, the normoxic cells began to show a senescent phenotype that included flattening of cells and expression of senescence-associated $\beta$-galactosidase (SA- $\beta$ gal) (Fig. 1C), while the hypoxic cells continued to proliferate logarithmically without slowing.

Excision of HIF $1 \alpha$ had a dramatic effect on these cells; the HIF $1 \alpha$-deficient cells grew slower in both conditions (Fig. 1B). In normoxia, the HIF $1 \alpha$-deficient cells barely proliferated throughout the assay and began to display the senescent phenotype almost immediately upon excision of HIFl $\alpha$. In fact, the fraction of SA- $\beta$ gal-positive cells in the HIF $1 \alpha$-deficient population was nearly four times than that in the wild-type population $(45 \%$ vs. $12 \%$ ) (Fig. 1D). We also confirmed that the decrease in cell number was due to lack of growth, as opposed to increased cell death, by annexin/PI staining. As expected, no significant cell death was evident in either cell population (Supplementary Fig. 1). Thus, HIF1 not only plays a role in the adaptation of cells to hypoxia, but unexpectedly also seems to play a role in normoxia by delaying the onset of senescence.

\section{MIF is a HIF1 $\alpha$-dependent, hypoxia-inducible gene}

In order to identify a potential mechanism for how HIF1 $\alpha$ delays senescence, we considered previously iden-
A
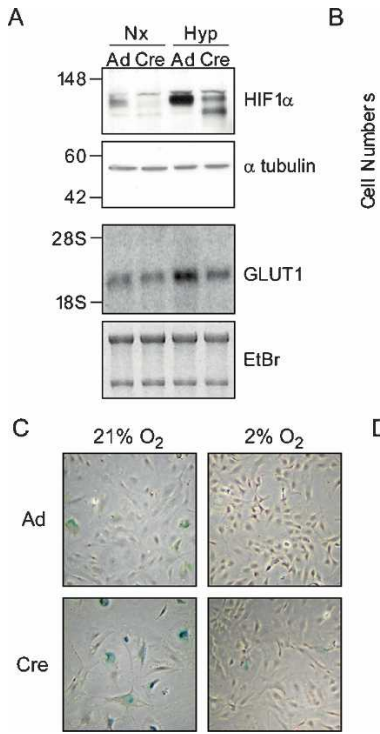

$B$

D
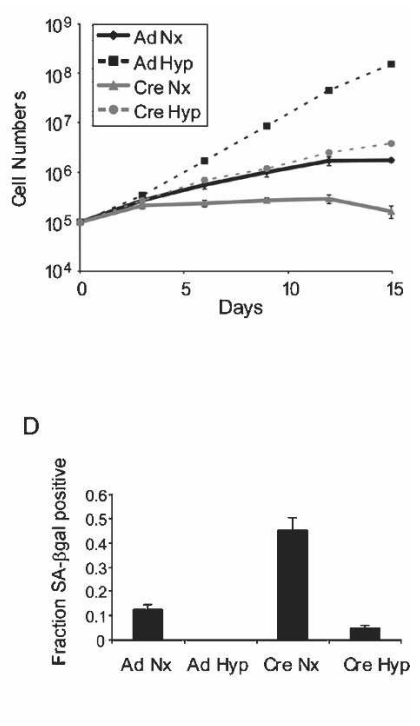

Figure 1. Loss of HIF $1 \alpha$ induces premature senescence in wild-type MEFs. (A) Western and Northern analyses of Ad-empty-infected (Ad) or Ad-Cre-infected (Cre) HIF $1 \alpha^{\mathrm{fl} / \mathrm{fl}}$ MEFs following $24 \mathrm{~h}$ incubation in either normoxia $\left(\mathrm{Nx}_{2}, 21 \% \mathrm{O}_{2}\right)$ or hypoxia $\left(\mathrm{Hyp}_{3} \% 2 \% \mathrm{O}_{2}\right)$. The top panels show immunoblots for HIFl $\alpha$ and for $\alpha$-tubulin as a loading control. Molecular weight markers in kilodaltons. The bottom panels show expression of the HIF1 $\alpha$ target gene GLUT1, and the ethidium bromide-stained gel as a loading control. $(B)$ Growth curves of Ad-empty-infected or Ad-Cre-infected HIF $1 \alpha^{\mathrm{fl} / \mathrm{fl}}$ MEFs grown in either normoxia or hypoxia. $(C)$ Representative photographs of SABgal staining of the cells in $B$ after the last counting time point. $(D)$ Quantitation of the SA- $\beta$ gal-positive fraction of cells in C. "Ad Nx" and "Cre $\mathrm{Nx}^{\prime}$ are statistically different by Student's $t$-test $(p=0.003)$. Error bars indicate standard deviation.

tified hypoxia-induced genes. One potential candidate is the macrophage MIF, which has been shown to negatively regulate p53 and prolong the life span of presenescent MEFs (Hudson et al. 1999; Fingerle-Rowson et al. 2003). Because MEFs derived from HIF $1 \alpha^{-/-}$animals can be immortalized with SV40 large $\mathrm{T}$ antigen, regulation of senescence by HIF $1 \alpha$ likely occurs upstream of p53 and $\mathrm{Rb}$ (Ryan et al. 1998). As a regulator of p53, MIF would therefore seem to be a potential link between hypoxia and senescence.

MIF was first found to be hypoxia inducible in a head and neck cancer cell line and in a cervical carcinoma cell line (Koong et al. 2000), and later in glial tumor cells (Bacher et al. 2003). In the latter study, the MIF promoter was found to be hypoxia inducible, suggesting regulation of MIF at the transcriptional level. How the promoter is regulated by hypoxia, however, was undetermined.

We first sought to determine if hypoxic regulation of MIF was dependent on HIF1 $\alpha$ by using HIF $1 \alpha$ knockout MEFs cultured under normoxic and hypoxic conditions. As seen in Figure 2A, GLUT1 mRNA is highly induced in wild-type cells but not in HIF1 $\alpha$-deficient cells following $24 \mathrm{~h}$ of hypoxia. MIF expression demonstrated the same behavior; and hypoxia-induced MIF mRNA translated into increased MIF protein as well (Fig. 2B). Interestingly, excision of HIFl $\alpha$ resulted in decreased expression of MIF (and to a lesser extent GLUT1) even in normoxic conditions, confirming the potential role for HIF1 in normoxia. Thus, we conclude that MIF regulation occurs at the transcriptional level, and is HIF $1 \alpha$ dependent. 


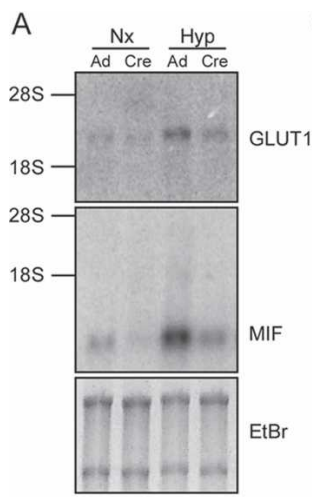

B

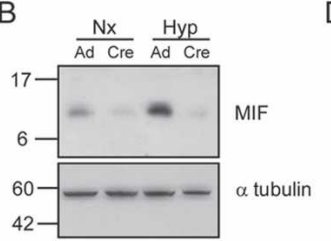

C

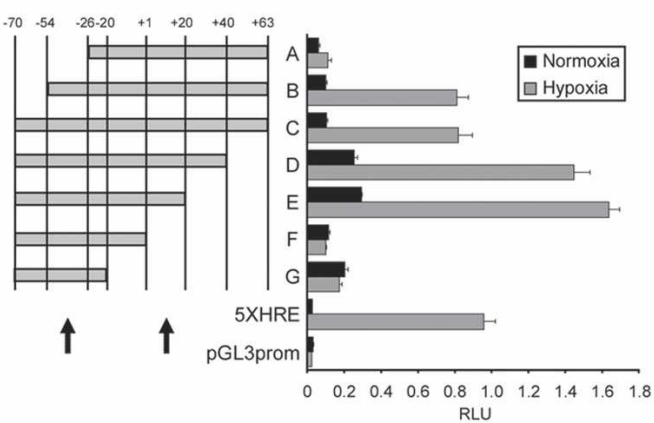

D

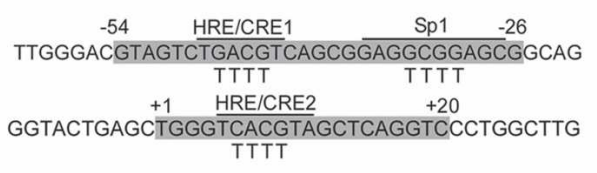

E

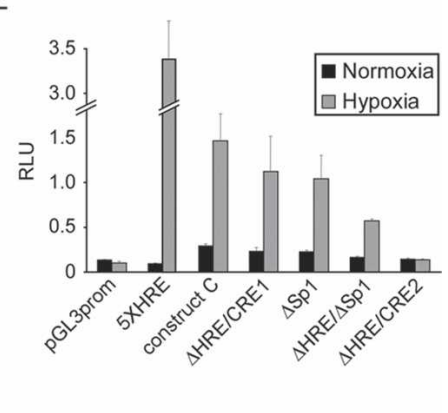

F

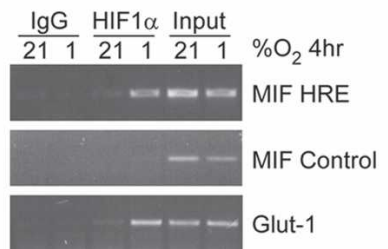

Figure 2. MIF is a HIFl $\alpha$-dependent hypoxia-inducible gene. (A) Northern analyses of Ad-empty-infected or Ad-Cre-infected HIF1 $\alpha^{\mathrm{fl} / \mathrm{fl}} \mathrm{MEFs}$ in normoxia $(\mathrm{Nx})$ or $2 \% \mathrm{O}_{2}$ (Hyp). GLUT1 and MIF transcript expression are shown, as well as the ethidium bromide-stained gel as a loading control. $(B)$ Western analyses of cells treated as in $A$. The immunoblots were probed with antibodies for MIF or $\alpha$-tubulin as indicated. Molecular weight markers in kilodaltons. $(C)$ Promoter analysis of the -70 to +63 region of the murine MIF promoter. Promoter fragments were cloned into pGL3promoter; a 5XHRE construct, including five copies of the human VEGF HRE, serves as a positive control. Constructs (identified by the letters A-G in the middle of the figure) are schematically represented in the bar diagram on the left, while their relative promoter activities in normoxia (black bars) and hypoxia (gray bars) are displayed on the right of the figure. Arrows at the bottom of the bar diagram indicate the regions that are essential for promoter activity. $(D)$ Promoter regions determined to be required for promoter activity in C. Putative promoter-binding sites were identified by computer database analysis (http://www.genomatrix.de). Four nucleotide mutations in the core of each site are indicated. $(E)$ Luciferase assays of construct $C$ with specific mutations identified in $D$. Mutations of the four core nucleotides of each site were made alone or in combination, as indicated at the bottom of the bar graph. $(F)$ ChIP analysis of the murine MIF promoter. Genomic DNA from the mouse keratinocyte cell line (Balb/MK) was fixed and immunoprecipitated with either IgG or an $\alpha$-HIF1 $\alpha$ antibody. Subsequently, PCR was performed with primers specific to the GLUT1 HRE, putative MIF HRE, or upstream MIF sequences (MIF control). Error bars indicate standard deviation.

In order to investigate how $\mathrm{HIF} 1 \alpha$ regulates MIF transcription, we cloned a $1-\mathrm{kb}$ fragment of the murine promoter that has been shown to be hypoxia inducible (Bacher et al. 2003) into pGL3basic, and performed deletion analyses and reporter assays. We found that HIF1 $\alpha$ overexpression alone was sufficient to activate the MIF promoter in normoxia (Supplementary Fig. 2). Large deletions revealed that the hypoxia inducibility of the promoter was dependent on two regions: one between -54 and -26 , and the other between the transcriptional start site and +20 (Fig. 2C; cf. constructs $\mathrm{A}$ and $\mathrm{B}$, and cf. constructs $\mathrm{E}$ and $\mathrm{F}$ ). These regions are denoted by arrows in Figure 2C. Based on promoter database analysis (http://www.genomatix.de), the former region contains a putative overlapping hypoxia response element (HRE) and cyclic-AMP response element (CRE), as well as an Sp1 site; while the latter contains a second putative HRE/CRE (Fig. 2D). Specific mutation of the HRE or the $\mathrm{Sp} 1$ sites alone in the upstream region did not ablate hypoxia responsiveness, but did reproducibly reduce hypoxic induction. Mutation of both sites together did, however, significantly reduce hypoxia responsiveness $(p<0.05)$ (Fig. 2E). These results suggest that the upstream HRE is not functional in the classical sense of a sequence specific promoter-binding site, or that HIF1 can be recruited either by direct DNA binding or through recruitment by a cofactor. In the latter case, it is notable that HIF1 and Sp1 have been found to cooperate in the induction of other hypoxia-inducible genes (Miki et al. 2004), and may be acting in this way on the MIF pro- moter. In the second region, mutation of the HRE/CRE completely abolished hypoxic induction (Fig. 2E), suggesting this site is a functional HRE. In accordance with this finding, Baugh et al. (2006) have recently reported a similar site in the human MIF promoter.

We next wanted to determine if HIFl $\alpha$ is capable of binding to the MIF promoter directly in vivo. To do so, we performed chromatin immunoprecipitation (ChIP) assays. Similar to the GLUT1 HRE, PCR amplification of DNA that coimmunoprecipitated with an anti-HIF1 $\alpha$ antibody compared with an IgG control resulted in specific enrichment of the MIF HRE region, but not a region $1 \mathrm{~kb}$ upstream ("MIF control") (Fig. 2F). These data suggest that HIF1 $\alpha$ is capable of binding the hypoxia responsive region of the MIF promoter directly in a living cell.

\section{MIF is necessary and sufficient to delay senescence of MEFs downstream from HIF1 $\alpha$}

To determine if expression of MIF is required to delay senescence, we designed a retroviral short hairpin RNA (shRNA) construct to stably knockdown MIF expression. MEFs were infected with this construct or a GFP control, selected, and then tested for MIF expression. As seen in Figure 3, A and B, our shRNA construct effectively knocked down the expression of MIF in both normoxic and hypoxic cells in a stable manner, while another hypoxia-induced gene (GLUT1) was unaffected and remained hypoxia inducible.

These cells were then plated and counted as before in 
A

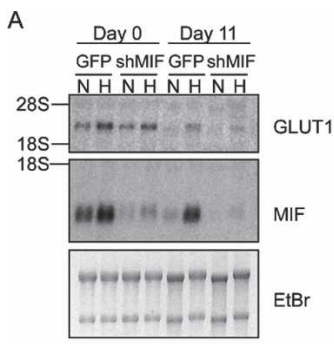

C

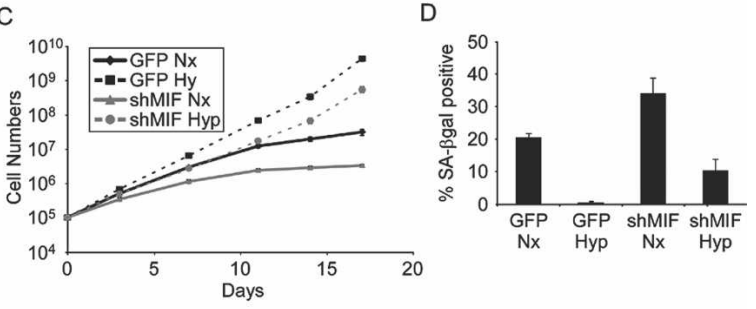

$E$

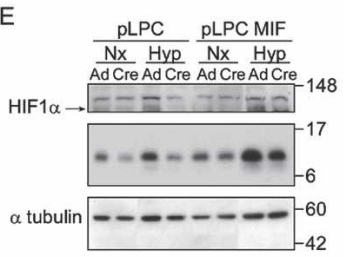

B
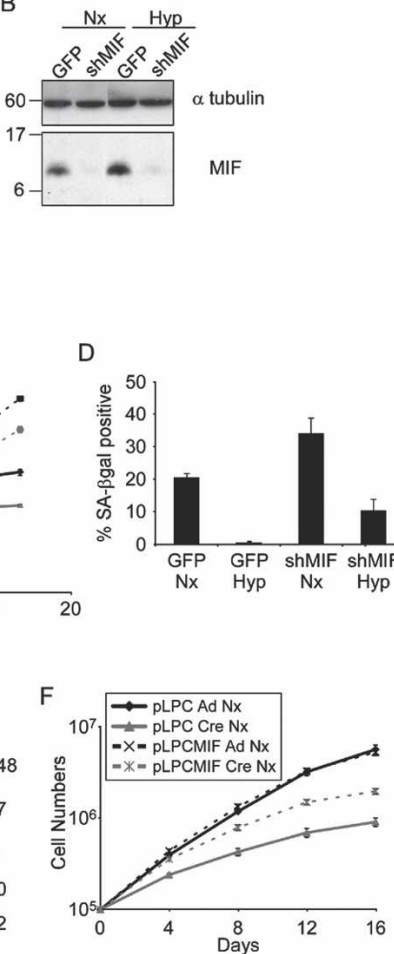

Figure 3. MIF is necessary and sufficient to delay senescence downstream from HIFl $\alpha$. (A) Northern blot demonstrating the knockdown of MIF using a retroviral shRNA in normoxic-treated $(\mathrm{N})$ and hypoxic-treated $(\mathrm{H})$ wild-type MEFs at day 0 and day 11 following selection. GLUT1 hybridization demonstrates that MIF knockdown does not markedly affect other HIF1 target genes. Ethidium bromide staining of the RNA demonstrates equal loading of the gel. (B) Western blot demonstrating the knockdown of MIF protein in normoxia $(\mathrm{Nx})$ and hypoxia (Hyp). $\alpha$-Tubulin is used as a loading control. Molecular weight in kilodaltons. $(C)$ Growth curves of MIF knockdown and control (GFP)-infected cells grown in normoxia ( $\mathrm{Nx}$ ) or $2 \% \mathrm{O}_{2}(\mathrm{Hyp}) .(D)$ Quantification of SA- $\beta$ gal staining of cells in $B$. "shMIF Nx" and "GFP Nx" are statistically different by Student's $t$-test $(p=0.022)$. (E) Western analysis of stable ectopic expression of MIF in MEFs following Ad-empty (Ad) or Ad-Cre (Cre) infection. Immunoblots for HIFl $\alpha$ (arrow), MIF, and $\alpha$-tubulin as a loading control are shown. pLPC refers to the empty vector backbone, compared with pLPCMIF, which expresses MIF. Molecular weight in kilodaltons. $(F)$ Growth curves of MIF-overexpressing cells following infection with Ad-empty or Ad-Cre in normoxia. Error bars indicate standard deviation.

a proliferation/senescence assay. As in the case of HIF $1 \alpha$, reduced expression of MIF caused a significant growth delay in hypoxia, and premature proliferative arrest in normoxia (Fig. 3C). This arrest correlated with increased SA-ßgal staining (Fig. 3D). In agreement with the growth curves, loss of MIF expression in normoxia caused a significant decrease in DNA synthesis, as determined by ${ }^{3} \mathrm{H}$-thymidine incorporation (Supplementary Fig. 3A). In addition, we found that this effect is dependent on p53. p53 ${ }^{-/-}$MEFs failed to demonstrate any deficiency in ${ }^{3} \mathrm{H}$ incorporation (Supplementary Fig. 3B-D). Together, these data suggest that expression of MIF is critical to avert p53-dependent cellular senescence.

To determine if MIF expression is sufficient to rescue premature senescence due to loss of $H I F 1 \alpha$, we next retrovirally transduced MIF into the conditional HIF1 $\alpha$ knockout MEFs. Following selection, these cells were infected with either Ad-Cre or Ad-empty as before to excise HIF1 $\alpha$ (Fig. 3E), and then plated in a senescence assay. As shown in Figure 3F, ectopic expression of MIF partially rescued the effect of loss of HIF1 $\alpha$ in normoxia. These data suggest that MIF is necessary and sufficient to delay senescence downstream from HIF $1 \alpha$. The lack of complete rescue, however, suggests the MIF may not be the only HIF1 $\alpha$ target gene involved in this response.

It is noteworthy that a role for MIF in regulating proliferation and senescence in MEFs has been previously suggested. MIF overexpression has been linked to a delay in senescence through a decrease in p53 activity in MEFs (Hudson et al. 1999). Additionally, embryonic fibroblasts have been isolated from MIF knockout mice. While these animals do not have any overt phenotype, MIFdeficient MEFs do display premature growth arrest at lower saturation densities (i.e., lower number of cells at confluence) (Fingerle-Rowson et al. 2003). While these results agree with our data in principle, the phenotype we have observed is more severe. In our studies MEFs demonstrate decreased DNA synthesis and proliferation immediately upon loss of MIF (Supplementary Fig. 3A). This difference may be attributable to a difference in chronic versus acute loss of MIF. It is possible that chronic loss of MIF results in a developmental compensation mechanism to deal with potentially higher p53 activity. This type of effect has been seen for the $\mathrm{Rb}$ family proteins, in which acute loss of $\mathrm{Rb}$ has a more severe effect than chronic loss owing to compensation by the Rb family member p107 (Sage et al. 2003). Thus, our studies, utilizing methodologies that result in acute loss of both HIF1 $\alpha$ and MIF, demonstrate a functional link between hypoxia, HIF1, and the regulation of senescence through MIF expression.

\section{Loss of HIF1 1 sensitizes MEFs to $\gamma$-irradiation under physiological oxygen concentrations}

Hypoxia and HIF1 are thought to play critical roles in the development of cancer. As solid tumors surpass a size of a few millimeters, they develop regions of severe hypoxia that lead to the optimal activation of HIF1 and its downstream target genes. HIF target genes are involved in crucial aspects of tumor development, including angiogenesis, metabolic adaptation, survival and metastasis. While there may be significant benefit to inhibiting HIF1 in tumors, our data suggest that there may also be significant effects in adjacent normal cells. As senescence in culture has been likened to aging in vivo (Campisi 2005), a reduction in HIF1 activity may lead to premature senescence and aging, particularly following therapeutic radiation exposure that results in severe oxidative stress.

To test the theory that loss of HIF1 activity would sensitize normal cells to radiation exposure under physiological oxygen concentrations $\left(2 \% \mathrm{O}_{2}\right)$, we subjected the HIF $1 \alpha^{\mathrm{fl} / \mathrm{fl}}$ MEFs infected with Ad-Cre or Ad-empty adenoviruses to sublethal doses of $\gamma$-irradiation (0.5 Gy or $2 \mathrm{~Gy}$. While we found that wild-type cells (infected with Ad-empty) were only moderately affected by these radiation doses, and did not display any arrest during the course of the assay, HIF1 $\alpha$-deficient cells demonstrated a substantial sensitization to radiation (Fig. 4A). After $12 \mathrm{~d}$ of culture in $2 \% \mathrm{O}_{2}$ following irradiation, both the 0.5 Gy- and 2 Gy-treated Cre-infected cells were more than eightfold fewer than their Ad-empty counterparts. Again, we confirmed that cell death was not occurring 


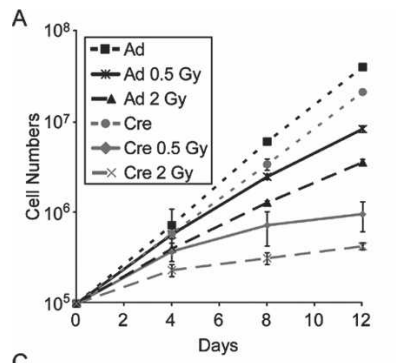

C

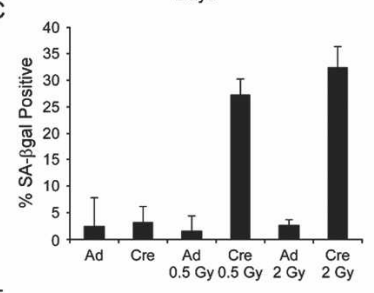

$E$

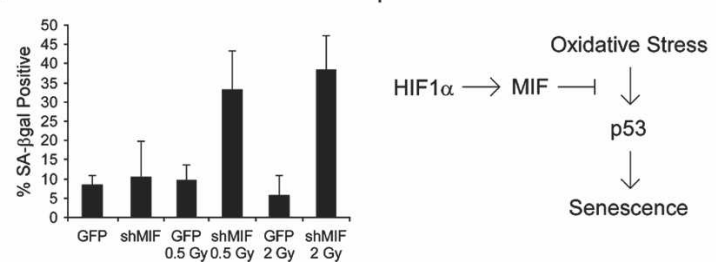

Figure 4. Loss of HIF1 activity sensitizes cells to radiation-induced senescence. (A) Growth curves of Ad-empty-infected or Ad-Cre-infected HIF $1 \alpha^{\mathrm{fl} / \mathrm{fl}} \mathrm{MEF}$ grown in $2 \% \mathrm{O}_{2}$ following treatment with 0.5 Gy or $2 \mathrm{~Gy}$ of radiation. (B) Representative photographs of SA- $\beta$ gal staining of the cells in $A$ after the last time point. $(C)$ Quantification of the SA-ßgal-positive cells in B. "Ad $0.5 \mathrm{~Gy}$ " and "Cre $0.5 \mathrm{~Gy}$ " are statistically different by Student's $t$-test $(p=0.0002)$; $\mathrm{Ad} 2 \mathrm{~Gy}^{\prime \prime}$ and "Cre 2 Gy" are also statistically different by Student's $t$-test $(p=0.0003)$. (D) Growth curves of GFP or shMIF MEFs grown in $2 \%$ $\mathrm{O}_{2}$ following treatment with 0.5 Gy or 2 Gy of radiation. (E) Quantification of the SA- $\beta$ gal-positive cells in $D 13 \mathrm{~d}$ after irradiation. "GFP 0.5 Gy" and "shMIF 0.5 Gy", and "GFP 2 Gy" and "shMIF 2 Gy" are both also statistically different by Student's $t$-test $(p<0.0001)$. (F) Model for the role of HIF1 $\alpha$ in modulating senescence through the regulation of MIF. Error bars indicate standard deviation.

by annexin/PI staining (Supplementary Fig. 1B). Furthermore, the HIF1 $\alpha$-deficient cells demonstrated significant SA- $\beta$ gal staining and assumed a senescent morphology (Fig. 4B). Greater than $27 \%$ of the Cre-infected cells stained positive for SA- $\beta$ gal following 0.5 Gy of radiation, and $>32 \%$ following 2 Gy of exposure. In contrast, the Ad-empty-infected cells showed only $1.4 \%$ and $2.4 \%$ blue cells, respectively (Fig. 4C). Thus, HIF1 loss sensitizes cells to radiation-induced senescence. Accordingly, we also found that knockdown of MIF similarly sensitizes cells (Fig. 4D,E). This result has direct implications for potential deleterious effects of combined therapies that involve HIF1 inhibition and radiation treatment. As MIF, in particular, has been implicated in other signaling pathways such as inhibition of apoptosis downstream from NF-кB (Talos et al. 2005), these results may also have implications in other systems.

Interestingly, it has been recently shown that radiation increases HIF1 activity in tumors, resulting in radiosensitization of tumor cells, but enhanced radioresistance of tumor vasculature (Moeller et al. 2004, 2005). These findings present a paradox regarding the use of HIF

inhibitors in combination with radiation therapy, since maintaining tumor vasculature also promotes tumor cell survival. In fact the authors of these papers suggest that scheduling will be of critical importance in order to achieve optimal therapeutic effects. In their studies, the beneficial effects on the endothelial cells seem to be mediated by the secretion of VEGF and bFGF (Moeller et al. 2005). In our studies, we demonstrate that HIF1 has a protective effect on cells by preventing premature senescence due to oxidative damage through the induction of the p53 regulator MIF (Fig. 4F). In fact, we found that in the absence of HIF1 $\alpha$, MEFs are more sensitive to the induction of p53 Ser 18 phosphorylation, and p21 expression following ionizing radiation (Supplementary Fig. 4). This provides a novel function of HIF1 in both atmospheric and physiological oxygen tensions, and highlights the need for further analysis of the potential effects of HIF inhibitors in vivo on both normal and malignant cells.

\section{Materials and methods}

Cell culture

$\mathrm{HIF} 1 \alpha^{\mathrm{fl} / \mathrm{fl}}$ MEFs were harvested using standard procedures from embryonic day 13.5 (E13.5) embryos as previously described (Serrano et al. 1997). Cells were grown for two population doublings and then frozen $(=\mathrm{p} 2.5)$. MEFs were carried in DMEM plus $10 \%$ fetal calf serum. Adenoviral infections were carried out at a multiplicity of infection (M.O.I.) of 100, with either Ad5CMVcre or Ad5CMVempty (Gene Transfer Vector Core, University of Iowa), three successive times over a 72 -h period. All hypoxia treatments were performed at $2 \% \mathrm{O}_{2}$, in a Ruskinn In $\mathrm{Vivo}_{2}$ Hypoxia Work Station (Biotrace International Plc). Cells were removed for trypsinization and counting. All protein and RNA extracts were harvested in the chamber. $\gamma$-Irradiation was carried out with an open-source ${ }^{137}$ Cesium irradiator.

\section{Constructs}

shRNA was performed using pSIREN-RetroQ (BD Biosciences). The MIF shRNA sequence was GATCCGCCGCAACTACAGTAAGCTGTTCA AGAGACAGCTTACTGTAGTTGCGGTTTTTTATCGATG. GFP was used as a control. Retroviruses were created using 293T Phoenix cells as previously described (Pear et al. 1993). The murine MIF cDNA was cloned into pLPCpuro for ectopic expression.

\section{ChIP assays}

ChIP assays were preformed essentially as described (Gustafsson et al. 2005). Primer sets are available upon request.

\section{Growth curves, SA-ßgal staining}

Cells $\left(10^{5}\right)$ were plated in triplicate in 6-cm plates and counted every 3-4 d. When growth arrest was apparent, cells were plated for SA- $\beta$ gal staining and stained as previously described (Dimri et al. 1995). Counts were made on three random fields of at least 100 cells.

\section{Northern blots and Western blots}

RNA was harvested using Trizol (Invitrogen) and processed according to the manufacture's recommendations. One microgram of RNA was loaded on denaturing formaldehyde $/ 1 \%$ agarose gels, transferred, and hybridized using standard methods. Protein lysates were made using a $9 \mathrm{M}$ Urea, 0.075 M Tris buffer ( $\mathrm{pH} 7.6)$, quantified with the Bradford assay, and run on SDS-PAGE using standard methods. Antibodies used were as follows: HIF1 $\alpha$, Bethyl Laboratories (A300-286A); MIF, Abcam (ab7207); $\alpha$-tubulin, RDI (TUBULAADM-DM); p53, Santa Cruz Biotechnology (DO-1, sc-126); p53Ser18, Cell Signaling (9284); $\beta$-actin, Santa Cruz Biotechnology (sc1615).

Reporter assays

Please see Supplemental Material.

\section{Acknowledgments}

We thank Dr. L. Attardi for p53 $3^{-/-}$MEFs; Dr. R. Johnson for the HIF $1 \alpha^{\mathrm{fl} / \mathrm{fl}}$ mice; and Drs. K. Bennewith, R. Freiberg, and T. Johnson for critical 
review of the manuscript. This work was funded by CA82466, CA67166, and CA088480.

\section{References}

Bacher, M., Schrader, J., Thompson, N., Kuschela, K., Gemsa, D., Waeber, G., and Schlegel, J. 2003. Up-regulation of macrophage migration inhibitory factor gene and protein expression in glial tumor cells during hypoxic and hypoglycemic stress indicates a critical role for angiogenesis in glioblastoma multiforme. Am. J. Pathol. 162: 11-17.

Baugh, J.A., Gantier, M., Li, L., Byrne, A., Buckley, A., and Donnelly, S.C. 2006. Dual regulation of macrophage migration inhibitory factor (MIF) expression in hypoxia by CREB and HIF-1. Biochem. Biophys. Res. Commun. 347: 895-903.

Bedogni, B., Welford, S.M., Cassarino, D.S., Nickoloff, B.J., Giaccia, A.J., and Powell, M.B. 2005. The hypoxic microenvironment of the skin contributes to Akt-mediated melanocyte transformation. Cancer Cell 8: 443-454.

Ben-Porath, I. and Weinberg, R.A. 2005. The signals and pathways activating cellular senescence. Int. J. Biochem. Cell Biol. 37: 961-976.

Braig, M., Lee, S., Loddenkemper, C., Rudolph, C., Peters, A.H., Schlegelberger, B., Stein, H., Dorken, B., Jenuwein, T., and Schmitt, C.A. 2005. Oncogene-induced senescence as an initial barrier in lymphoma development. Nature 436: 660-665.

Campisi, J. 2005. Senescent cells, tumor suppression, and organismal aging: Good citizens, bad neighbors. Cell 120: 513-522.

Chen, Z., Trotman, L.C., Shaffer, D., Lin, H.K., Dotan, Z.A., Niki, M., Koutcher, J.A., Scher, H.I., Ludwig, T., Gerald, W., et al. 2005. Crucial role of p53-dependent cellular senescence in suppression of Ptendeficient tumorigenesis. Nature 436: 725-730.

Collado, M., Gil, J., Efeyan, A., Guerra, C., Schuhmacher, A.J., Barradas, M., Benguria, A., Zaballos, A., Flores, J.M., Barbacid, M., et al. 2005. Tumour biology: Senescence in premalignant tumours. Nature 436: 642.

Dimri, G.P., Lee, X., Basile, G., Acosta, M., Scott, G., Roskelley, C., Medrano, E.E., Linskens, M., Rubelj, I., Pereira-Smith, O., et al. 1995. A biomarker that identifies senescent human cells in culture and in aging skin in vivo. Proc. Natl. Acad. Sci. 92: 9363-9367.

Fingerle-Rowson, G., Petrenko, O., Metz, C.N., Forsthuber, T.G., Mitchell, R., Huss, R., Moll, U., Muller, W., and Bucala, R. 2003. The p53-dependent effects of macrophage migration inhibitory factor revealed by gene targeting. Proc. Natl. Acad. Sci. 100: 9354-9359.

Gustafsson, M.V., Zheng, X., Pereira, T., Gradin, K., Jin, S., Lundkvist, J., Ruas, J.L., Poellinger, L., Lendahl, U., and Bondesson, M. 2005. Hypoxia requires notch signaling to maintain the undifferentiated cell state. Dev. Cell 9: 617-628.

Hudson, J.D., Shoaibi, M.A., Maestro, R., Carnero, A., Hannon, G.J., and Beach, D.H. 1999. A proinflammatory cytokine inhibits p53 tumor suppressor activity. J. Exp. Med. 190: 1375-1382.

Kato, H., Inoue, T., Asanoma, K., Nishimura, C., Matsuda, T., and Wake, N. 2006. Induction of human endometrial cancer cell senescence through modulation of HIF- $1 \alpha$ activity by EGLN1. Int. J. Cancer 118: 1144-1153.

Kim, W.Y. and Kaelin, W.G. 2004. Role of VHL gene mutation in human cancer. J. Clin. Oncol. 22: 4991-5004

Koong, A.C., Denko, N.C., Hudson, K.M., Schindler, C., Swiersz, L., Koch, C., Evans, S., Ibrahim, H., Le, Q.T., Terris, D.J., et al. 2000. Candidate genes for the hypoxic tumor phenotype. Cancer Res. 60: 883-887.

Lee, A.C., Fenster, B.E., Ito, H., Takeda, K., Bae, N.S., Hirai, T., Yu, Z.X., Ferrans, V.J., Howard, B.H., and Finkel, T. 1999. Ras proteins induce senescence by altering the intracellular levels of reactive oxygen species. J. Biol. Chem. 274: 7936-7940.

Lowe, S.W., Cepero, E., and Evan, G. 2004. Intrinsic tumour suppression. Nature 432: 307-315.

Michaloglou, C., Vredeveld, L.C., Soengas, M.S., Denoyelle, C., Kuilman, T., van der Horst, C.M., Majoor, D.M., Shay, J.W., Mooi, W.J., and Peeper, D.S. 2005. BRAFE600-associated senescence-like cell cycle arrest of human naevi. Nature 436: 720-724.

Miki, N., Ikuta, M., and Matsui, T. 2004. Hypoxia-induced activation of the retinoic acid receptor-related orphan receptor $\alpha 4$ gene by an interaction between hypoxia-inducible factor-1 and Sp1. J. Biol. Chem. 279: 15025-15031.
Moeller, B.J., Cao, Y., Li, C.Y., and Dewhirst, M.W. 2004. Radiation activates HIF-1 to regulate vascular radiosensitivity in tumors: Role of reoxygenation, free radicals, and stress granules. Cancer Cell 5: 429-441.

Moeller, B.J., Dreher, M.R., Rabbani, Z.N., Schroeder, T., Cao, Y., Li, C.Y., and Dewhirst, M.W. 2005. Pleiotropic effects of HIF-1 blockade on tumor radiosensitivity. Cancer Cell 8: 99-110.

Narita, M., Nunez, S., Heard, E., Lin, A.W., Hearn, S.A., Spector, D.L., Hannon, G.J., and Lowe, S.W. 2003. Rb-mediated heterochromatin formation and silencing of E2F target genes during cellular senescence. Cell 113: 703-716.

Park, S.K., Dadak, A.M., Haase, V.H., Fontana, L., Giaccia, A.J., and Johnson, R.S. 2003. Hypoxia-induced gene expression occurs solely through the action of hypoxia-inducible factor $1 \alpha(\mathrm{HIF}-1 \alpha)$ : Role of cytoplasmic trapping of HIF-2 $\alpha$. Mol. Cell. Biol. 23: 4959-4971.

Parrinello, S., Samper, E., Krtolica, A., Goldstein, J., Melov, S., and Campisi, J. 2003. Oxygen sensitivity severely limits the replicative lifespan of murine fibroblasts. Nat. Cell Biol. 5: 741-747.

Pear, W.S., Nolan, G.P., Scott, M.L., and Baltimore, D. 1993. Production of high-titer helper-free retroviruses by transient transfection. Proc. Natl. Acad. Sci. 90: 8392-8396.

Ryan, H.E., Lo, J., and Johnson, R.S. 1998. HIF-1 $\alpha$ is required for solid tumor formation and embryonic vascularization. EMBO J. 17: 30053015.

Ryan, H.E., Poloni, M., McNulty, W., Elson, D., Gassmann, M., Arbeit, J.M., and Johnson, R.S. 2000. Hypoxia-inducible factor- $1 \alpha$ is a positive factor in solid tumor growth. Cancer Res. 60: 4010-4015.

Sage, J., Miller, A.L., Perez-Mancera, P.A., Wysocki, J.M., and Jacks, T. 2003. Acute mutation of retinoblastoma gene function is sufficient for cell cycle re-entry. Nature 424: 223-228.

Schofield, C.J. and Ratcliffe, P.J. 2004. Oxygen sensing by HIF hydroxylases. Nat. Rev. Mol. Cell Biol. 5: 343-354.

Serrano, M., Lin, A.W., McCurrach, M.E., Beach, D., and Lowe, S.W. 1997. Oncogenic ras provokes premature cell senescence associated with accumulation of p53 and p16INK4a. Cell 88: 593-602.

Sharpless, N.E. and DePinho, R.A. 2005. Cancer: Crime and punishment. Nature 436: 636-637.

Sherr, C.J. and DePinho, R.A. 2000. Cellular senescence: Mitotic clock or culture shock? Cell 102: 407-410.

Stewart, F.A., Denekamp, J., and Randhawa, V.S. 1982. Skin sensitization by misonidazole: A demonstration of uniform mild hypoxia. Br. J. Cancer 45: 869-877.

Talos, F., Mena, P., Fingerle-Rowson, G., Moll, U., and Petrenko, O. 2005. MIF loss impairs Myc-induced lymphomagenesis. Cell Death Differ. 12: 1319-1328.

Vaupel, P., Kallinowski, F., and Okunieff, P. 1989. Blood flow, oxygen and nutrient supply, and metabolic microenvironment of human tumors: A review. Cancer Res. 49: 6449-6465. 


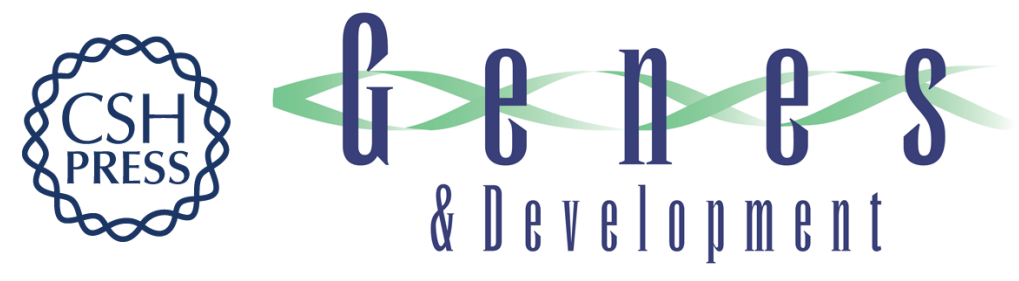

\section{HIF1 $\alpha$ delays premature senescence through the activation of MIF}

Scott M. Welford, Barbara Bedogni, Katarina Gradin, et al.

Genes Dev. 2006, 20: originally published online December 1, 2006

Access the most recent version at doi:10.1101/gad.1471106

\footnotetext{
Supplemental http://genesdev.cshlp.org/content/suppl/2006/12/04/gad.1471106.DC1

Material

Related Content HIF and MIFa nifty way to delay senescence?

Amit Maity and Constantinos Koumenis

Genes Dev. December , 2006 20: 3337-3341

References This article cites 35 articles, 12 of which can be accessed free at: http://genesdev.cshlp.org/content/20/24/3366.full.html\#ref-list-1

Articles cited in:

http://genesdev.cshlp.org/content/20/24/3366.full.html\#related-urls

License

Email Alerting

Service

Receive free email alerts when new articles cite this article - sign up in the box at the top right corner of the article or click here.
}

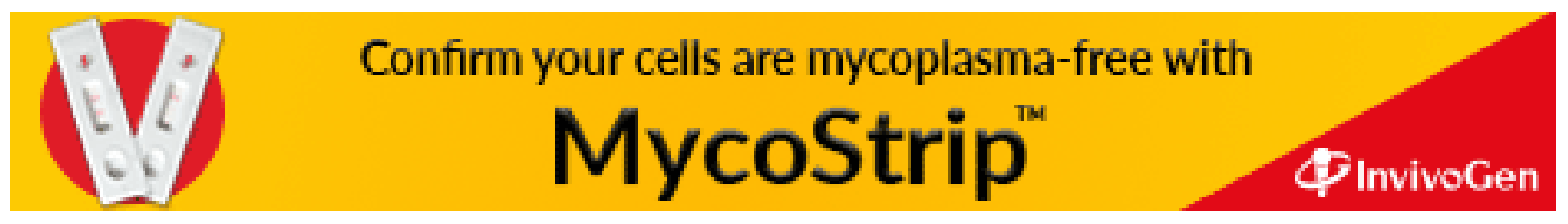

